Retrospective Study

\title{
Evaluation of an Experimental Pain Model by Noncompartmental Analysis of Results from a Randomized Placebo Controlled Trial
}

Sybil Skinner-Robertson, BSN, PhD¹, Mohamad-Samer Mouksassi, PharmD, $\mathrm{PhD}^{1,2}$, and France Varin, $\mathrm{PhD}^{1}$

From: ${ }^{1}$ Faculté de pharmacie, Université de Montréal, Québec,

Canada; ${ }^{2}$ Certara Consulting Services, Montréal, Québec,

Canada

Address Correspondence: France Varin, PhD

Faculté de Pharmacie

Université de Montréal 2940 chemin de la Polytechnique Montréal, Québec, Canada $\left.\mathrm{H}_{3} \mathrm{~T}_{1}\right)_{4}$ E-mail: france.varin@umontreal.ca

Disclaimer: Sybil SkinnerRobertson was an employee of Labopharm Inc. prior to Nov 2011. France Varin and Mohamad-Samer Mouksassi have no conflicts of interest.

The study was contracted by Labopharm Inc. MDS Pharma conducted the clinical portions of the PK study. Labopharm sponsored the conduct of the

study but not the analyses presented herein

Manuscript received: 05-29-2017 Revised manuscript received: 01-14-2018

Accepted for publication: 01-19-2018

Free full manuscript: www.painphysicianjournal.com
Background: Understanding analgesic pharmacodynamics (PD) in the elderly is key to optimising pain management. Electrically stimulated pain models (ESPM) permit assessment of pain responses in humans. $C$ and $A \delta$ sensory fibres convey pain and respond to low frequency electrical stimulus (5 and $250 \mathrm{~Hz}$, respectively). Human research suggests pain tolerance threshold (PTT) is similar or decreases with age.

Objectives: To determine whether an ESPM is able to detect a difference in PTT in elderly ( $\geq$ 75 years) and young (20-40 years) subjects after single dose administration of a placebo and tramadol, a low potency analgesic.

Study Design: Two-cohort, randomized, placebo-controlled, cross-over study.

Methods: A noncompartmental analysis of data at 17 timepoints on $5 \mathrm{~Hz}$ and $250 \mathrm{~Hz}$ PTT over $24 \mathrm{~h}$

Results: Young (16) and elderly (13) patients showed similar baseline (E0) PTT between active and placebo both overall and by age group in both frequencies. Net drug effect took into account negative and positive changes from E0. In the elderly, net peak effect on PTT produced by active treatment was significantly greater for both $5 \mathrm{~Hz}(34 \%)$ and $250 \mathrm{~Hz}(30 \%)$. Net area under the 24-h effect-time curve during active treatment was significantly higher for both $5 \mathrm{~Hz}(163 \%)$ and $250 \mathrm{~Hz}(175 \%)$ stimulations in the elderly. No clinically significant difference was observed in the young.

Limitations: High variability in young subjects, despite efforts to remove outliers limited our ability to draw conclusions in that age group. Generalizability of results obtained from an experimental pain model in volunteers to treatment of elderly patients may be limited.

Conclusion: ESPM can detect a difference for pain tolerance threshold between placebo and tramadol administration in the elderly. Although both $5 \mathrm{~Hz}$ and $250 \mathrm{~Hz}$ stimulations can detect a difference, the effect size for $5 \mathrm{~Hz}$ is larger and seems more precise and reliable, particularly in the elderly.

Key words: Electrical pain model, elderly, geriatric, tramadol, placebo, opioid, area under the effect curve, noncompartmental analysis

Pain Physician 2018: 21:363-372
D ain is a complex sensory, affective and cognitive experience. Determination of analgesic efficacy in humans using animal models only gives part of the picture while results from clinical trials are affected by concomitant medications and coexisting morbidities. Human experimental pain models offer the opportunity to assess human responses to pain in a more controlled setting using objective measures. 
Electrically Stimulated Pain Models (ESPMs) can selectively activate different afferents and nervous structures and thereby evoke various pain sensations (1). The reliability of ESPM to detect differences in current perception threshold has recently been established for potent post-operative analgesia (2). However, differences in pain tolerance threshold (PTT) have not been established for a low potency analgesic such as tramadol and not in an elderly study population.

With age peripheral nerves display structural, functional and biochemical changes that primarily affect $A \delta$ and $C$-fibres. Electrical current stimulation predominantly stimulates $C, A \delta$ and $A \beta$ fibres (3). $C$ and $A \delta$ fibres are high threshold afferents which convey pain and temperature sensations (4) and which respond to low frequency electrical stimulus (e.g., 5 and $250 \mathrm{~Hz}$, respectively) after several milliseconds of continuous depolarization. Previous work has demonstrated the utility of an ESPM at $5 \mathrm{~Hz}$ in determining sensory blockade with ropivacaine, a potent local anesthetic, before and after orthopedic surgery $(5,6)$. Furthermore, ESPMs have been used to study analgesic response in a variety of strong opioids including morphine, alfentanil and remifentanil (7-10).

Tramadol is a centrally acting analgesic which demonstrates weak opioid action and modifies descending pain transmission through inhibition of monamine reuptake. Its analgesic potency is comparable to codeine and dextropropoxyphene $(11,12)$. Although optimizing pain management in the elderly requires a systematic understanding of the pharmacodynamics (PD) of analgesics in the elderly, few studies have been conducted to assess the efficacy and safety of analgesics in this population $(13,14)$. Pharmacokinetics (PK) have been studied but a quantitative tool that would allow PK/PD studies of analgesics vs. subjective assessment is needed. Data from a study utilizing an ESPM to assess differences between young and elderly patients with regard to pain tolerance of transcutaneous electrical stimuli at $250 \mathrm{~Hz}$ and $5 \mathrm{~Hz}$ are presented here. The objective of these exploratory analyses is to examine whether the ESPM utilized in the study is able to detect a difference in elderly and young patients at $5 \mathrm{~Hz}$ and $250 \mathrm{~Hz}$ after a single dose of placebo and tramadol.

\section{Methods}

\section{Experimental Design}

Drug effect data from a study conducted between January and February 2007 that was intended to evaluate the PK and PD after a single dose of tramadol Contramid ER tablets in elderly ( $\geq 75$ years) and healthy young (18-40 years) volunteers are analyzed and presented here. This 2-cohort, double-blind, randomized, placebo-controlled, cross-over, study used an ESPM to evaluate PTT. Patients received either a single oral dose of $200 \mathrm{mg}$ tramadol contramid OAD controlled-release tablets or identical placebo with a 7-day washout between each period. The study was conducted at a phase 1 facility (MDS Pharma Services, Montreal, Quebec) where patients were confined for 12 hours prior to dosing and for 48 hours afterwards. The sequence of administration was randomized and double blinded. Each patient was assigned a unique identification number and received the corresponding product according to a randomization scheme taking into account age to ensure an equal number of young and elderly patients in each treatment sequence.

Noncompartmental (NCA) and population PK analyses were reported in an earlier publication (15). Data from this study is used here to assess the ability of $5 \mathrm{~Hz}$ and $250 \mathrm{~Hz}$ transcutaneous electrical stimuli to detect a difference in PTT response between placebo and active treatment in young and elderly patients. A future publication, will present a PK/PD analysis of 0 -desmethyltramadol, tramadol's active metabolite, in young versus elderly patients(16).

Before initiation of the study, the protocol and informed consent for this study were reviewed and approved by 2 independent ethics committees (Comité d'Ethique de la Recherche des Sciences de la Santé, Université de Montréal; and Investigational Review Board, MDS Pharma Services, Montreal). All patients provided their written informed consent prior to the initiation of any study-related procedures. The study was conducted in accordance with the Declaration of Helsinki as well as the Enoncé de politique des trois Conseils. The study is registered and details of the protocol are available at clinicaltrials.gov (NCT02329561).

\section{Patients}

At screening, patients were determined to be healthy based on medical history, physical examination, and evaluation of vital signs, electrocardiogram (ECG), and clinical laboratory data. Patients with an increased risk of seizures or conditions that would affect sensory nerve conduction were excluded as tramadol lowers the seizure threshold. Patients with bowel disease affecting absorption or previous failure of treatment with tramadol or discontinuation of treatment due 
to adverse events were also excluded. Female patients of childbearing potential had to have negative pregnancy test results at screening and clinic check-in for each study period. Use of all medication (including over-the-counter products) was prohibited for 7 days prior to dosing and during the time of sample collection with 2 exceptions: elderly patients were permitted to continue taking stable doses of chronic medications, other than strong CYP inhibitors/inducers, and female patients were permitted to continue taking hormonal contraception or replacement therapy. Use of any nonexcluded concomitant medications was recorded.

\section{Pharmacodynamic Evaluations}

PD data were collected using the Neurometer CPT/C (Neurotron, Inc., Baltimore, MD, USA), a fully automated quantitative neuro-diagnostic device that generates constant alternating current sinusoid waveform stimuli at 3 different calibrated frequencies $(2000 \mathrm{~Hz}, 250 \mathrm{~Hz}$ and $5 \mathrm{~Hz}$ ). The device has a possible range from 0.01 milliAmperes (mA) to $10 \mathrm{~mA}$ (with an automatic cut-off at 10mA) (17-19). The Neurometer was used to measure PTT which was defined as the maximum amount in $\mathrm{mA}$ of the atraumatic neuroselective electrical stimulus that a volunteer was willing to tolerate. We utilized the 250 $\mathrm{Hz}$ and $5 \mathrm{~Hz}$ stimulus to selectively target, respectively, $A \delta$ and $C$ fibres which convey pain and temperature sensations (4). We did not use the $2000 \mathrm{~Hz}$ frequency which stimulates fibres that convey information about touch and pressure since we are testing a pain model (4).

Prior to administering tramadol, we ensured that the patients were familiar with the electrical stimulus procedure, sensations they might experience and how to stop the test if they wished to. On the evening prior to their first dose, patients received training during which they had at least 2 practice procedures.

In order to administer the painful stimulus, $21-\mathrm{cm}$ diameter gold-plated surface electrodes linked to the Neurometer were applied to the non-dominant middle finger of each subject during data collection sessions. If cuts, scrapes, contusions, healing wounds or other signs of recent trauma were present on the non-dominant middle finger, the dominant middle finger or non-dominant index finger were used. Electrical stimulations were conducted at the following times: prior to dosing and at $0.33,0.75,1.25,1.75,2.5,3.5,4.5,5.5,7,9,11,14$, 20, 24 and 30 hours after dosing. Stimulations occurred at least 5 minutes apart and at each time point, the 250 $\mathrm{Hz}$ stimulation was applied first. Since the study also collected PK data, the ESPM ratings were conducted prior to PK sampling to avoid influencing the patients' pain tolerance. Patients were isolated from each other by means of cardboard dividers during data collection periods; noise and other stimuli were kept to a minimum and patients were asked to remain sitting and minimise physical activity during the first 4 hours after administration of tramadol.

\section{Data}

All recorded data from the PD evaluations were entered into Microsoft Excel 2010 (Microsoft Corporation, Redmond, WA) and double verified for accuracy. Initial cleaning of the database to remove duplicates and obvious outliers (20) as well as initial establishment of baseline was conducted prior to unblinding of the data. Initially we intended to utilise the value recorded at Time $0\left(t_{0}\right)$ for baseline. However, visual inspection of the data demonstrated large variability in PTT for both $5 \mathrm{~Hz}$ and $250 \mathrm{~Hz}$ in the early sampling times and after 24 hours. Therefore, baseline for each period was estimated from the values at $t_{0}$ and the last recorded value (21). Data after 24 hours were not used for the noncompartmental analysis to ensure that measurable tramadol concentrations would be observed in all patients in the active period thus providing a meaningful comparison with the placebo period.

\section{Analyses}

\section{Demographic Analysis}

Descriptive statistics including mean, median, standard deviation (SD) and range were calculated for demographic variables using Sigmaplot 11.0 (Systat Software, San Jose, CA).

\section{Pharmacodynamic Analysis}

A noncompartmental analysis was conducted to describe the PTT in young and elderly patients during placebo and active administration phases using model 220 of Phoenix WinNonlin version 6.4 software (Certara USA, Inc., Princeton, NJ). The dependent variable, PTT after $5 \mathrm{~Hz}$ and $250 \mathrm{~Hz}$ stimulations, were provided at time of observation as well as at dosing time. Determination of baseline response $\left(E_{0}\right)$ was carried out as described above for each administration phase (active or placebo). For each patient and administration phase (active or placebo), individual area under the effecttime curve (AUEC) between 0 and $24 \mathrm{~h}$ was calculated using the linear trapezoidal rule. Both positive and negative fluctuations from the predetermined baseline 
response were taken into account during integration and calculated as $A U E C_{\text {above }}$ and $A U E C_{\text {below' }}$ respectively. Summation of all positive and negative AUEC yielded AUEC $_{\text {net }}$. Maximum effect $\left(E_{\text {max }}\right)$, Time to maximum effect $\left(T_{\text {max }}\right)$, Time above baseline $\left(T_{\text {above }}\right)$, and percentage change from $E_{0}$ to $E_{\text {max }}\left(\Delta E_{\text {max }}(\%)\right)$ were also analyzed.

A linear mixed effect regression model (LMEM) (Phoenix WinNonlin version 6.4) was utilized to compare the results amongst the age and administration phases to determine whether the ESPM at each stimulus frequency was able to detect a difference between placebo and active administration phases and between those administration phases in young and elderly patients. Least squares means (LSM) point estimates for each parameter and for the difference between the parameters overall, by age and by administration phase were calculated along with standard error of the means, 95\% confidence intervals (Cl) and $P$-values (significant $<0.05$ ). To compare our data with the literature on placebo effect, Cohen's $d$ for $E_{\max }$ was calculated as follows: (mean $E_{\max }$ for active (A) - mean $E_{\max }$ for placebo (P)) / Standard Deviation (SD) for pooled; SD pooled was calculated as $\sqrt{ }\left(\mathrm{SD}_{\mathrm{A}}+\mathrm{SD}_{\mathrm{P}}\right) / 2(22)$.

Table 1. Baseline demographics.

\begin{tabular}{|c|c|c|}
\hline & $\begin{array}{c}\text { Young } \\
(18-40 \text { years }) \\
n=16\end{array}$ & $\begin{array}{c}\text { Elderly } \\
\text { ( } \geq 75 \text { years) } \\
\text { n }=13\end{array}$ \\
\hline $\begin{array}{l}\text { Gender } \mathrm{n}(\%)^{\mathrm{a}} \\
\text { Male } \\
\text { Female }\end{array}$ & $\begin{array}{c}13(81) \\
3(19)\end{array}$ & $\begin{array}{c}10(77) \\
3(23)\end{array}$ \\
\hline $\begin{array}{l}\text { Weight }(\mathrm{kg}) \\
\text { Mean } \pm \text { SD } \\
\text { Range }\end{array}$ & $\begin{array}{l}74 \pm 10 \\
59-98\end{array}$ & $\begin{array}{c}78 \pm 7 \\
65-93\end{array}$ \\
\hline $\begin{array}{l}\text { BMI }\left(\mathrm{kg} / \mathrm{m}^{2}\right)^{\mathrm{b}} \\
\text { Mean } \pm \text { SD } \\
\text { Range }\end{array}$ & $\begin{array}{c}25 \pm 2 \\
21-27 \\
\end{array}$ & $\begin{array}{c}28 \pm 3 \\
25-35 \\
\end{array}$ \\
\hline $\begin{array}{l}\text { GFR }(\mathrm{mL} / \\
\left.\mathrm{min} / 1.73 \mathrm{~m}^{2}\right)^{\mathrm{c}} \\
\text { Mean } \pm \mathrm{SD} \\
\text { Range }\end{array}$ & $\begin{array}{l}103 \pm 14 \\
78-135\end{array}$ & $\begin{array}{l}68 \pm 12 \\
50-90\end{array}$ \\
\hline
\end{tabular}

SD - Standard Deviation; BMI - Body Mass Index; GFR - Glomerular Filtration Rate

aPercentage of patients who are male or female within the age group ${ }^{\mathrm{b}}$ The difference in BMI between the age-groups was statistically significant $(P<0.001)$

${ }^{\mathrm{c}} \mathrm{GFR}$ was calculated using serum creatinine according to the CKDEPI (Chronic Kidney Disease Epidemiology Collaboration) formula. The difference between the age groups was statistically significant $(P$ $<0.001)$

\section{Results}

\section{Demographics}

A total of 20 young and 15 elderly patients were recruited between December 2006 and February 2007 and enrolled in the study. One subject from the elderly group discontinued early in the first period due to personal reasons and was excluded from the analyses. Five patients, 4 from the young group and 1 from the elderly group, were excluded from analyses due to a food effect as described in detail in Skinner Robertson et al's previous report (15). The analyses presented here included 29 healthy young and elderly patients (Table 1) most of whom were male. In the first cohort of patients, a concealed electrical panel at the research clinic interfered with the functioning of one of the neurostimulation devices by spontaneously shutting it down at times before PTT was reached and thereby delaying data acquisition (less than $10 \mathrm{~min}$ ). The issue was resolved by the time the second cohort was brought to the clinic for testing. Despite this, there was no statistically significant cohort effect. Patients were followed for safety for 30 days following their last dose in the study.

\section{Comparison of Active and Placebo Period in Patients Regardless of Age Group}

Table 2 presents the data observed for effect at $E_{0}$ and $\mathrm{E}_{\max }$ and $\Delta \mathrm{E}_{\max }(\%)$. The data are presented for all patients and by age group for active and placebo as the LSM point estimate (mean) and difference of the means with the $95 \%$ confidence interval. All point estimates and all differences in the means were within the $95 \%$ $\mathrm{Cl}$.

Adverse events reported by at least $10 \%$ of patients are presented in Table 3.

Both when all patients were considered and when the age groups were compared, there were no differences by administration phase (placebo vs. active) at baseline $\left(E_{0}\right)$ for PTT under $5 \mathrm{~Hz}$ or $250 \mathrm{~Hz}$ stimulation.

Maximum effect and $\Delta \mathrm{E}_{\max }(\%)$ were significantly greater in the active versus placebo administration phases for both $5 \mathrm{~Hz}$ and $250 \mathrm{~Hz}$ stimulations when patients were compared regardless of age group (Table 2).

The results of the noncompartmental analysis of the data by treatment regardless of age group are presented as Whisker plots in Fig. 1. For both $5 \mathrm{~Hz}$ and 250 $\mathrm{Hz}$ stimulations, the point estimate for the difference between active and placebo means was statistically higher for $\mathrm{AUEC}_{\text {above }}$ after $5 \mathrm{~Hz}(511,95 \% \mathrm{Cl}$ [152-871]; $54 \%$ relative increase) and $250 \mathrm{~Hz}(566,95 \% \mathrm{Cl}$ [141- 
Table 2. Least square mean PTT and difference of means for $5 \mathrm{~Hz}$ and $250 \mathrm{~Hz}$ stimulations during active and placebo administration phases.

\begin{tabular}{|c|c|c|c|c|c|c|c|}
\hline \multirow[b]{2}{*}{ Parameter } & \multirow[b]{2}{*}{ Patients } & \multicolumn{3}{|c|}{$5 \mathrm{~Hz}$} & \multicolumn{3}{|c|}{$250 \mathrm{~Hz}$} \\
\hline & & $\begin{array}{c}\text { Placebo } \\
\text { LSM } \\
{[95 \% \text { CI }]} \\
\end{array}$ & $\begin{array}{c}\text { Active } \\
\text { LSM } \\
{[95 \% \text { CI }]} \\
\end{array}$ & $\begin{array}{c}\text { Difference of } \\
\text { the means } \\
{[95 \% \mathrm{CI}]}\end{array}$ & $\begin{array}{c}\text { Placebo } \\
\text { LSM } \\
{[95 \% \text { CI }]} \\
\end{array}$ & $\begin{array}{c}\text { Active } \\
\text { LSM } \\
{[95 \% \text { CI }]} \\
\end{array}$ & $\begin{array}{c}\text { Difference of } \\
\text { the means } \\
{[95 \% \mathrm{CI}]}\end{array}$ \\
\hline \multirow[t]{3}{*}{$\mathrm{E}_{0}(\mathrm{uA})$} & $\begin{array}{c}\text { All } \\
\mathrm{n}=29\end{array}$ & $\begin{array}{c}142 \\
{[104-180]}\end{array}$ & $\begin{array}{c}143 \\
{[106-181]}\end{array}$ & $\begin{array}{c}1.28 \\
{[-14-16]}\end{array}$ & $\begin{array}{c}202 \\
{[157-247]}\end{array}$ & $\begin{array}{c}201 \\
{[156-246]}\end{array}$ & $\begin{array}{c}-1.25 \\
{[-28-26]}\end{array}$ \\
\hline & $\begin{array}{l}\text { Young } \\
\mathrm{n}=16\end{array}$ & $\begin{array}{c}142 \\
{[104-180]}\end{array}$ & $\begin{array}{c}140 \\
{[89-190]}\end{array}$ & $\begin{array}{c}-2.42 \\
{[-22-17]}\end{array}$ & $\begin{array}{c}216 \\
{[156-277]}\end{array}$ & $\begin{array}{c}198 \\
{[137-258]}\end{array}$ & $\begin{array}{c}-18 \\
{[-54-16]}\end{array}$ \\
\hline & $\begin{array}{l}\text { Elderly } \\
\mathrm{n}=13\end{array}$ & $\begin{array}{c}142 \\
{[86-198]}\end{array}$ & $\begin{array}{c}147 \\
{[91-203]}\end{array}$ & $\begin{array}{c}4.97 \\
{[-18-28]}\end{array}$ & $\begin{array}{c}187 \\
{[137-258]}\end{array}$ & $\begin{array}{c}204 \\
{[136-271]}\end{array}$ & $\begin{array}{c}16 \\
{[-26-58]}\end{array}$ \\
\hline \multirow[t]{3}{*}{$\mathrm{E}_{\max }(\mathrm{uA})$} & $\begin{array}{c}\text { All } \\
n=29\end{array}$ & $\begin{array}{c}240 \\
{[177-304]}\end{array}$ & $\begin{array}{c}281 \\
{[217-345]}\end{array}$ & $\begin{array}{c}41^{\star} \\
{[14-67]}\end{array}$ & $\begin{array}{c}310 \\
{[229-392]}\end{array}$ & $\begin{array}{c}354 \\
{[272-436]}\end{array}$ & $\begin{array}{c}43^{*} \\
{[3.33-84]}\end{array}$ \\
\hline & $\begin{array}{l}\text { Young } \\
\mathrm{n}=16\end{array}$ & $\begin{array}{c}246 \\
{[161-331]}\end{array}$ & $\begin{array}{c}249 \\
{[164-334]}\end{array}$ & $\begin{array}{c}2.51 \\
{[-32-37]}\end{array}$ & $\begin{array}{c}343 \\
{[234-453]}\end{array}$ & $\begin{array}{c}348 \\
{[239-457]}\end{array}$ & $\begin{array}{c}4.31 \\
{[-48-56]}\end{array}$ \\
\hline & $\begin{array}{l}\text { Elderly } \\
\mathrm{n}=13\end{array}$ & $\begin{array}{c}235 \\
{[140-329]}\end{array}$ & $\begin{array}{c}313 \\
{[219-408]}\end{array}$ & $\begin{array}{c}79^{*} \\
{[37-120]}\end{array}$ & $\begin{array}{c}277 \\
{[155-399]}\end{array}$ & $\begin{array}{c}360 \\
{[239-482]}\end{array}$ & $\begin{array}{c}83^{*} \\
{[21-145]}\end{array}$ \\
\hline \multirow[t]{3}{*}{$\Delta \mathrm{E}_{\max }(\%)$} & $\begin{array}{c}\text { All } \\
\mathrm{n}=29\end{array}$ & $\begin{array}{c}81 \\
{[61-101]}\end{array}$ & $\begin{array}{c}111 \\
{[91-131]}\end{array}$ & $\begin{array}{c}29^{*} \\
{[6-53]}\end{array}$ & $\begin{array}{c}55 \\
{[39-70]}\end{array}$ & $\begin{array}{c}79 \\
{[63-94]}\end{array}$ & $\begin{array}{c}24^{*} \\
{[12-34]}\end{array}$ \\
\hline & $\begin{array}{l}\text { Young } \\
\mathrm{n}=16\end{array}$ & $\begin{array}{c}77 \\
{[51-104]}\end{array}$ & $\begin{array}{c}84 \\
{[58-110]}\end{array}$ & $\begin{array}{c}7 \\
{[-23-37]}\end{array}$ & $\begin{array}{c}63 \\
{[42-83]}\end{array}$ & $\begin{array}{c}80 \\
{[60-101]}\end{array}$ & $\begin{array}{c}17^{*} \\
{[3-31]}\end{array}$ \\
\hline & $\begin{array}{l}\text { Elderly } \\
\mathrm{n}=13\end{array}$ & $\begin{array}{c}85 \\
{[55-115]}\end{array}$ & $\begin{array}{c}137 \\
{[108-167]}\end{array}$ & $\begin{array}{c}52^{\star} \\
{[16-88]}\end{array}$ & $\begin{array}{c}47 \\
{[24-70]}\end{array}$ & $\begin{array}{c}77 \\
{[54-100]}\end{array}$ & $\begin{array}{c}30^{*} \\
{[13-47]}\end{array}$ \\
\hline
\end{tabular}

${ }^{*} P$ value < 0.05 LSM: least squares mean; PTT: pain tolerance threshold; $\mathrm{E}_{0}$ : baseline PTT; CI: confidence interval; $\mathrm{E}_{\max }: \operatorname{maximum~PTT;} \Delta \mathrm{E}_{\max }$ (\%): percent difference between $\mathrm{E}_{\max }$ and $\mathrm{E}_{0}$ values

991]; $58 \%$ relative increase); for AUEC $_{\text {net }}$ after $5 \mathrm{~Hz}(612$, $95 \% \mathrm{Cl}$ [223-1002]; 75\% relative increase) and $250 \mathrm{~Hz}$ (625, 95\% Cl [183-1068]; 57\% relative increase); and, Time $_{\text {above }}$ after $5 \mathrm{~Hz}(4.14 \mathrm{~h}, 95 \% \mathrm{Cl}[1.38-6.90 \mathrm{~h}] ; 22 \%$ relative increase) and $250 \mathrm{~Hz}(3.37 \mathrm{~h} 95 \% \mathrm{Cl}$ [0.79-5.95h]; $18 \%$ relative increase). $\mathrm{AUEC}_{\text {below }}$ was significantly lower only for stimulation with $5 \mathrm{~Hz}$.

\section{Comparison of Active and Placebo Phase by Age Group}

Mean results by stimulation frequency, administration phase and age group are presented in Table 2. All point estimates and means were within the $95 \% \mathrm{Cl}$. The $\mathrm{SE}$ is lower in the $5 \mathrm{~Hz}$ group consistently.

For $\mathrm{E}_{0}$, no differences were observed between placebo and active administration phase in the young and elderly groups under either $5 \mathrm{~Hz}$ or $250 \mathrm{~Hz}$ stimulation (Table 2). In elderly patients, there was a significantly higher $\mathrm{E}_{\max }$ and $\Delta \mathrm{E}_{\max }$ during the active administration phase after both $5 \mathrm{~Hz}$ and $250 \mathrm{~Hz}$ stimulations while a higher $\Delta \mathrm{E}_{\max }$ (but not $\mathrm{E}_{\max }$ ) was observed during active administration phase in young patients only after 250 $\mathrm{Hz}$ stimulation (Table 2).
Table 3. Most commonly reported adverse events ${ }^{a}$ by age group and active or placebo treatment (15).

\begin{tabular}{|l|c|c|c|c|}
\hline \multirow{2}{*}{ Adverse event } & \multicolumn{2}{|c|}{ Young $(\mathbf{n}=\mathbf{2 0})$} & \multicolumn{2}{c|}{ Elderly $(\mathbf{n}=\mathbf{1 5})$} \\
\cline { 2 - 5 } & Active & Placebo & Active & Placebo \\
\hline Nausea & $9(45)$ & $0(0.0)$ & $2(10)$ & $1(7.1)$ \\
\hline Dizziness & $7(35)$ & $0(0.0)$ & $3(15)$ & $1(7.1)$ \\
\hline Vomiting & $5(25)$ & $0(0.0)$ & $3(15)$ & $0(0.0)$ \\
\hline Somnolence & $2(10)$ & $0(0.0)$ & $2(10)$ & $0(0.0)$ \\
\hline
\end{tabular}

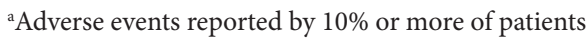

${ }^{b}$ Number and percentage of subjects experiencing the adverse event at least once

Whisker plots of the results of the NCA by stimulation frequency, administration phase and age group are presented in Fig. 2. For the $5 \mathrm{~Hz}$ stimulation, the interquartile range (IQR) was greater in young patients, particularly during placebo administration, with the exception of $A \cup C_{\text {below. }}$. For the $250 \mathrm{~Hz}$ stimulation, the IQR was greater in young patients than elderly patients, with the exception of AUEC $_{\text {net* }}$.

In young patients, difference in the point estimate between the means for active versus placebo adminis- 


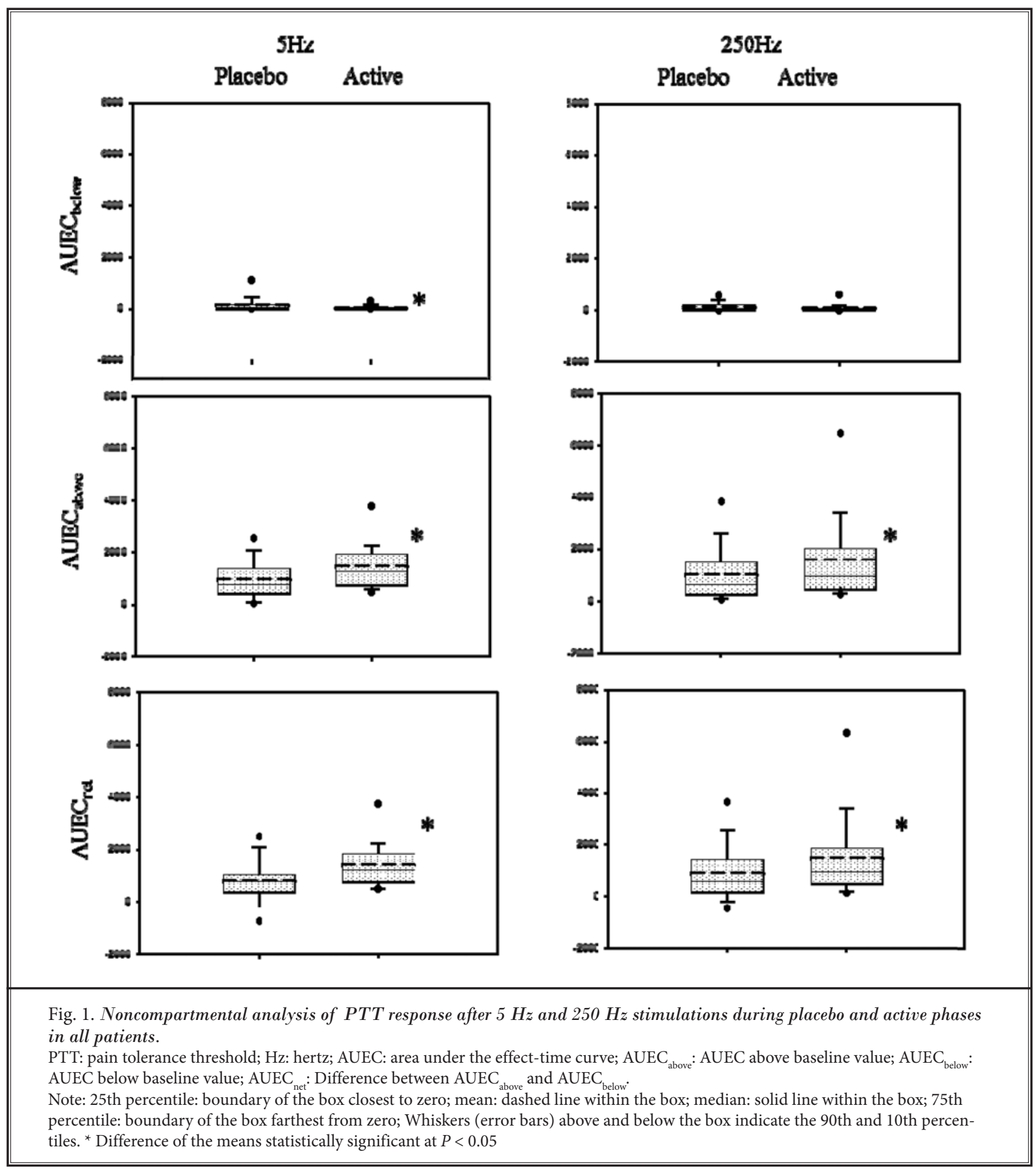

tration phases were not statistically different for AUE$C_{\text {above' }}$ AUEC $C_{\text {net }}$ and AUEC $C_{\text {below. }}$.

In elderly patients, the point estimate for the difference between the means showed a significantly higher AUEC $_{\text {above }}(5 \mathrm{~Hz}: 906$ mA, 95\% Cl [355-1457] relative difference: $118 \%$ higher; $250 \mathrm{~Hz}: 695,95 \%$ $\mathrm{Cl}$ [44-1347] relative difference: $116 \%$ higher or two-fold difference), and AUEC $_{\text {net }}(5 \mathrm{~Hz}: 1009 \mathrm{~mA}$, 95\% Cl [412-1606] relative difference: $163 \%$ higher or almost 3-fold difference; $250 \mathrm{~Hz}$ : $734 \mathrm{~Hz}, 95 \%$ 


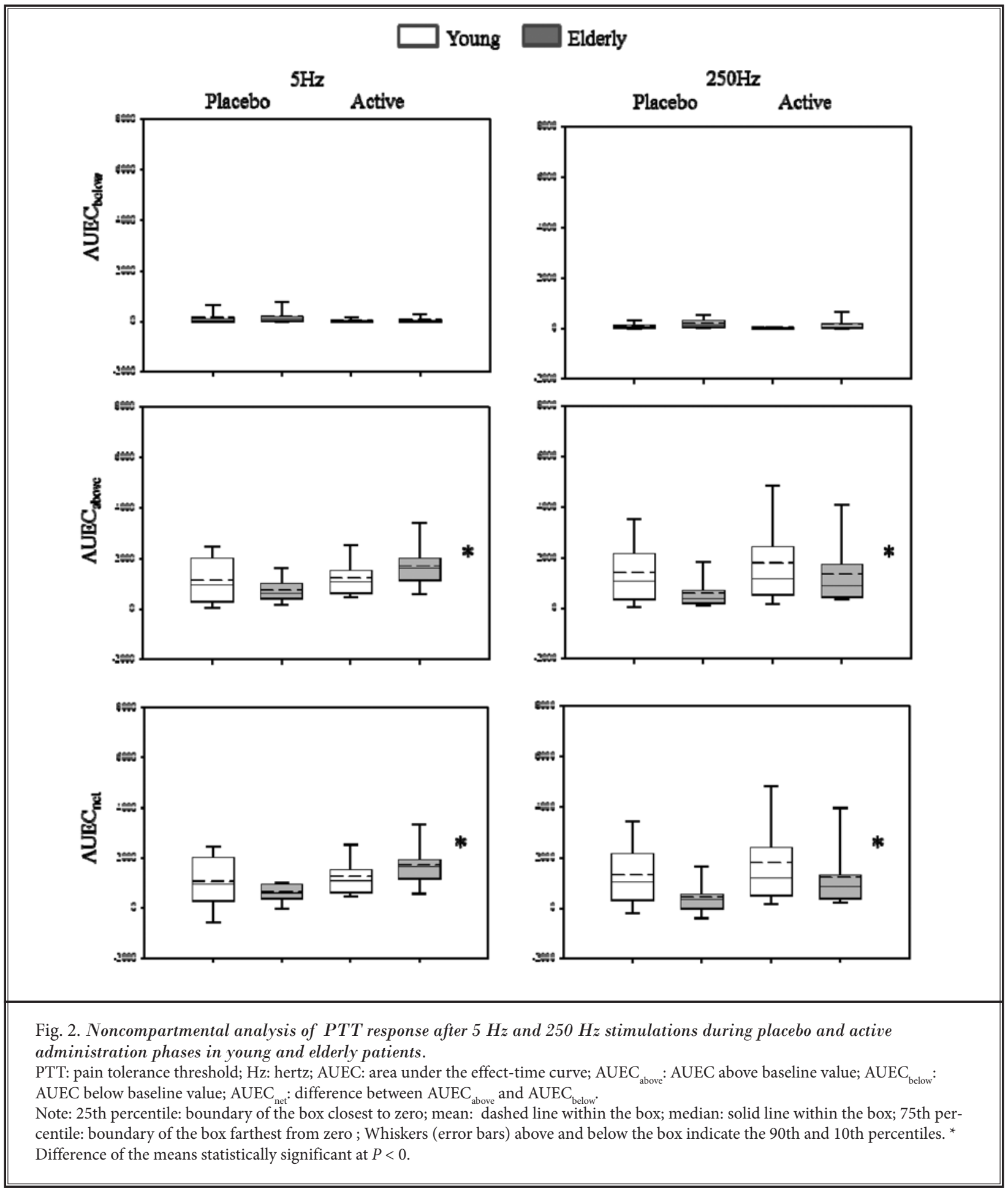

$\mathrm{Cl}$ [56-1412] relative difference: $175 \%$ higher or almost 3-fold difference) during active administration for both $5 \mathrm{~Hz}$ and $250 \mathrm{~Hz}$ stimulation. Time above $_{\text {was }}$ significantly longer only for the $5 \mathrm{~Hz}$ stimulation in elderly patients $(5 \mathrm{~Hz}$ : $5.02 \mathrm{~h}, 95 \% \mathrm{Cl}$ [0.80-9.26] relative increase: $35 \%$ higher). 


\section{Discussion}

The objective of this analysis was to determine whether the ESPM, using the 5 or $250 \mathrm{~Hz}$ frequency, was able to capture changes in tolerance to pain intensity using PTT after the administration of a weak opioid in healthy volunteers. During analysis, we also explored whether an age-related difference in response existed between elderly and young patients. This study demonstrated that in elderly patients an ESPM is able to detect a difference in pain tolerance between placebo and active administration phases. Although the difference can be detected for both $5 \mathrm{~Hz}$ and $250 \mathrm{~Hz}$, the effect size for $5 \mathrm{~Hz}$ is larger and seems more precise and reliable particularly in the elderly.

Although currently open to debate, placebo control in clinical studies is traditionally accepted by the scientific community as the best way to determine the true effect of a medication, based on the premise that there is an underlying effect of placebo and that true medication effect is additive to that of the placebo effect (23). Placebo response is highly variable and depends on many contextual factors (22), this is particularly true in analgesic studies and therefore our study had a placebo control arm.

To ensure that the ESPM was able to detect a difference between active and placebo administration phases, we first examined the data by administration phase (placebo vs. active) without taking into consideration age group and found no significant differences at baseline in PTT between the active and placebo groups with either frequency. In our study, when patients were administered placebo the maximum value for PTT over baseline $\left(\Delta \mathrm{E}_{\max }\right)$ was increased by $81 \%$. Vase et al (22), in their meta-analysis of 21 articles published between 2002 and 2007, found a highly variable magnitude of placebo analgesia with effect size calculated using Cohen's $D$ ranging from 0.12 to 2.51 . The average effect size in studies where placebo is used as a control for various conditions ranged from 0.15 to $0.27(22,24-26)$. In our study, it was 0.25 and 0.11 for the $5 \mathrm{~Hz}$ and 250 $\mathrm{Hz}$ stimuli, respectively. When comparing active administration phase versus placebo, the ESPM was able to detect a maximum relative increase from baseline of $29 \%$ and $24 \%$ for the $5 \mathrm{~Hz}$ and $250 \mathrm{~Hz}$ electrical stimulations, respectively. Similarly, AUEC $_{\text {above }^{\prime}}$ which is a pharmacodynamic measure of exposure (duration $x$ amplitude of positive effect) increased by $75 \%$ for both frequencies. Thus, the ESPM was adequately able to detect a difference between placebo and active admin- istration phases at either stimulation frequency.

There were no statistically significant differences either regardless of age or when age was taken into account when the data and analyses for the $5 \mathrm{HZ}$ and $250 \mathrm{~Hz}$ stimulations were compared. The confidence intervals for differences in the means were consistently narrower for the $5 \mathrm{~Hz}$ analyses suggesting that we are able to more accurately estimate the difference in the 5 $\mathrm{Hz}$ data. This could be because the sensation caused by the $5 \mathrm{~Hz}$ stimulation is more unpleasant and therefore easier to recognize consistently.

When analyses were conducted to take into account the age-related differences in pain tolerance, there were no significant differences in $\mathrm{E}_{0}$ between the age groups with $5 \mathrm{~Hz}$ or $250 \mathrm{~Hz}$ stimulation. Studies in humans, in general, have drawn inconsistent conclusions with regard to the purported increase in pain perception and the decrease in pain tolerance in the elderly (27). In experimental studies the modality of the painful stimulus seems to play a key role. Pain perception has been shown to decrease with thermally induced pain (28-31) and increase with mechanically induced pain $(32,33)$. Results of published studies of age related changes in pain tolerance using electrical nociceptive stimuli are less clear with one demonstrating a no change (34), 2 demonstrating reduced pain perception. Our exploratory results for pain tolerance showed baseline PTT in elderly showing a trend to be lower than in the young.

Data in the young group failed to demonstrate significance against placebo in any of the analyses except for $\Delta \mathrm{E}_{\max }$ after $250 \mathrm{~Hz}$ stimulation. The clinical significance of this observation is debatable as no difference was observed between active and placebo AUECs in young patients. In our opinion, AUEC is a more robust indicator of the persistence of effect. The point estimates for the mean AUEC $_{\text {above }}$ and $A U E C_{\text {net }}$ were consistently higher in the elderly during active administration phase for both $5 \mathrm{~Hz}$ and $250 \mathrm{~Hz}$ stimulations. A plausible reason for the fact that only elderly patients showed a consistent and sustained increase in PTT during the active phase was identified in our previous noncompartmental PK analysis where a $30 \%$ higher exposure to (+)-0-Desmethyltramadol (+-ODM) was observed in elderly patients (15). As this metabolite is associated with much of the opioid analgesic effect of tramadol, this would roughly correspond to the $30 \%$ higher AUEC $_{\text {above }}$ and AUEC $_{\text {net }}$ observed in the elderly compared to young during the active period. 
Within the elderly age group, the analyses showed that while both the $5 \mathrm{~Hz}$ and $250 \mathrm{~Hz}$ ESPM were able to reliably detect a difference between active and placebo administration phases, variability was smaller in the 5 $\mathrm{Hz}$ results for the elderly. The greater reliability of the $5 \mathrm{~Hz}$ versus the $250 \mathrm{~Hz}$ frequency could be particularly relevant in the elderly age group due to changes in the detection, processing and modulation of pain signals related to age. Age related structural and functional impairment in peripheral nerves is most notable in $A-\delta$ fibres which are selectively stimulated by the $250 \mathrm{~Hz}$ frequency of the Neurometer $(19,27,35)$. Therefore, the $5 \mathrm{~Hz}$ data will form the basis for future PK/PD modeling of the data.

\section{Limitations}

For most measures, variability is higher in the young group with both the IQR (25\% and $75 \%)$ and the 10th and 90th percentile error bars usually being greater. This is evident despite efforts to remove outliers during early visual inspection of the data. We speculate that the greater variability is a result of a desire of some of the younger patients to test whether their pain tolerance would be higher than the cut-off limit of the Neurometer apparatus. Including an older young group, such as 30-50 year olds may have reduced the attempts to test the limits of the machine and reduced variability. Since the objective of the ESPM is to demon- strate changes in pain tolerance and not the maximum tolerance of a given individual, anchoring the rating to a visual analog scale to help the patients more consistently determine their PTT could have further reduced variability. Also, elderly patients are more experienced in gauging their pain tolerance.

Finally, one may also question the generalizability of the results obtained from an experimental pain model conducted in volunteers to treatment of elderly patients. However, Olesen et al suggest that experimental pain models offer the opportunity to study pain responses when they are not blurred by other symptoms and where confounding environmental circumstances are as controlled as possible (1). Development of a population PK/PD model that links the ESPM to the concentrations of O-desmethyltramadol will be important future work to determine how age related factors affect the pain response of elderly patients administered tramadol.

\section{Conclusions}

After single dose administration to healthy young and elderly patients, ESPM is able to detect a difference between placebo and active administration phases for pain tolerance threshold in the elderly. Although both $5 \mathrm{~Hz}$ and $250 \mathrm{~Hz}$ can detect a difference, the effect size for $5 \mathrm{~Hz}$ is larger and seems more precise and reliable particularly in the elderly.

\section{References}

1. Olesen AE, Andresen T, Staahl C, Drewes AM. Human experimental pain models for assessing the therapeutic efficacy of analgesic drugs. Pharmacol Rev 2012; 64:722-779.

2. Gaudreault F, Drolet P, Fallaha $M$, Varin $F$. The reliability of the current perception threshold in volunteers and its applicability in a clinical setting. Anesthesia Q Analgesia 2015; 120:678-683.

3. Gustorff B, Hoerauf KH, Lierz P, Kress HG. Comparison of different quantitative sensory testing methods during remifentanil infusion in volunteers. $\mathrm{Br}$ ] Anaesth 2003; 91:203-208.

4. Djouhri L, Lawson SN. Abeta-fiber nociceptive primary afferent neurons: a review of incidence and properties in relation to other afferent A-fiber neurons in mammals. Brain Res Rev 2004;
46:131-145.

5. Gaudreault F, Drolet P, Fallaha M, Varin F. A population pharmacokinetic model for the complex systemic absorption of ropivacaine after femoral nerve block in patients undergoing knee surgery. J Pharmacokinet Pharmacodyn 2012; 39:635-642.

6. Gaudreault F, Drolet P, Fallaha M, Varin F. Modeling the anesthetic effect of ropivacaine after a femoral nerve block in orthopedic patients: A population pharmacokinetic-pharmacodynamic analysis. Anesthesiology 2015; 122:1010-1020.

7. Sarton E, Olofsen E, Romberg R, den Hartigh J, Kest B, Nieuwenhuijs D, Burm A, Teppema L, Dahan A. Sex differences in morphine analgesia: An experimental study in healthy volunteers. Anesthesiology 2000; 93:1245-1254; discussion.
8. Skarke C, Darimont J, Schmidt $H$, Geisslinger G, Lotsch J. Analgesic effects of morphine and morphine-6-glucuronide in a transcutaneous electrical pain model in healthy volunteers. Clin Pharmacol Ther 2003; 73:107-121.

9. Olofsen E, Romberg R, Bijl H, Mooren R, Engbers F, Kest B, Dahan A. Alfentanil and placebo analgesia: No sex differences detected in models of experimental pain. Anesthesiology 2005; 103:130-139.

10. Rohdewald P, Granitzki HW, Neddermann E. Comparison of the analgesic efficacy of metamizole and tramadol in experimental pain. Pharmacology 1988; 37:209-217.

11. Lehmann KA, Kratzenberg U, Schroeder-Bark B, Horrichs-Haermeyer G. Postoperative patient-controlled analgesia with tramadol: Analgesic efficacy and 
minimum effective concentrations. Clin J Pain 1990; 6:212-220.

12. Lee CR, McTavish D, Sorkin EM. Tramadol. A preliminary review of its pharmacodynamic and pharmacokinetic properties, and therapeutic potential in acute and chronic pain states. Drugs 1993; 46:313-340.

13. Paladini A, Fusco M, Coaccioli S, Skaper SD, Varrassi G. Chronic pain in the elderly: The case for new therapeutic strategies. Pain Physician 2015; 18:E863-E876.

14. McLachlan AJ, Bath S, Naganathan V, Hilmer SN, Le Couteur DG, Gibson SJ, Blyth F M. Clinical pharmacology of analgesic medicines in older people: Impact of frailty and cognitive impairment. Br J Clin Pharmacol 2011; 71:351-364.

15. Skinner-Robertson S, Fradette C, Bouchard S, Mouksassi MS, Varin F. Pharmacokinetics of tramadol and odesmethyltramadol enantiomers following administration of extended-release tablets to elderly and young subjects. Drugs Aging 2015; 32:1029-1043.

16. Skinner-Robertson S, Mouksassi, M.S., Varin, F. Population PK/PD modeling of O-desmethyltramadol in young and elderly healthy volunteers. Submitted to Drugs and Aging. [Accepted for publication]

17. Neurotron I. Neurometer ${ }^{\circledR}$ CPT: Sensory Nerve Conduction Threshold Device Measuring Neuroselective Current Perception Thresholds, Testing Sites, Version 3.3. Baltimore, MD: Neurotron Inc; (2003).

18. Neurotron I. Neurometer ${ }^{\circledR}$ CPT/C Device Operating Manual. Baltimore, MD: Neurotron Inc 1999.

19. J K. Electrodiagnostic functional sen- sory evaluation of the patient with pain: A review of the neuroselective current perception threshold and pain tolerance. Pain Digest 1998; 8:219-239.

20. Mould DR, Upton RN. Basic concepts in population modeling, simulation, and model-based drug development-part 2: Introduction to pharmacokinetic modeling methods. CPT Pharmacometrics Syst Pharmacol 2013; 2:e38:1-14.

21. Scheff JD, Almon RR, Dubois DC, Jusko WJ, Androulakis IP. Assessment of pharmacologic area under the curve when baselines are variable. Pharm Res 2011; 28:1081-1089.

22. Vase L, Petersen GL, Riley JL, 3rd, Price DD. Factors contributing to large analgesic effects in placebo mechanism studies conducted between 2002 and 2007. Pain 2009; 145:36-44.

23. Enck P KS, Weimer K, Horing B, Zipfel $S$. The placebo response in clinical trials: More questions than answers. Philosophical Transactions of the Royal Society B: Biological Sciences. 2011; 366:1889-1895.

24. Vase L, Riley JL, 3rd, Price DD. A comparison of placebo effects in clinical analgesic trials versus studies of placebo analgesia. Pain 2002; 99:443-452.

25. Hrobjartsson A, Gotzsche PC. Is the placebo powerless? Update of a systematic review with 52 new randomized trials comparing placebo with no treatment. J Intern Med 2004; 256:91-100.

26. Hrobjartsson A, Gotzsche PC. Is the placebo powerless? An analysis of clinical trials comparing placebo with no treatment. N Engl J Med 2001; 344:1594-1602.

27. Kemp J, Despres O, Pebayle T, Dufour A. Age-related decrease in sensitiv- ity to electrical stimulation is unrelated to skin conductance: An evoked potentials study. Clin Neurophysiol 2014; 125:602-607.

28. Chakour MC, Gibson SJ, Bradbeer M, Helme RD. The effect of age on A delta- and C-fibre thermal pain perception. Pain 1996; 64:143-152.

29. Chapman WP, Jones CM. Variations in cutaneous and visceral pain sensitivity in normal subjects. J Clin Invest 1944; 23:81-91.

30. Gibson SJ, LeVasseur SA, Helme RD. Cerebral event-related responses induced by $\mathrm{CO}_{2}$ laser stimulation in subjects suffering from cervico-brachial syndrome. Pain 1991; 47:173-182.

31. Lariviere M, Goffaux P, Marchand S, Julien N. Changes in pain perception and descending inhibitory controls start at middle age in healthy adults. Clin J Pain 2007; 23:506-510.

32. Lautenbacher $S$, Kunz $M$, Strate $P$, Nielsen J, Arendt-Nielsen L. Age effects on pain thresholds, temporal summation and spatial summation of heat and pressure pain. Pain 2005; 115:410-418.

33. Pickering G, Jourdan D, Eschalier A, Dubray C. Impact of age, gender and cognitive functioning on pain perception. Gerontology 2002; 48:112-118.

34. Mylius V, Kunz M, Hennighausen E, Lautenbacher S, Schepelmann K. Effects of ageing on spinal motor and autonomic pain responses. Neurosci Lett 2008; 446:129-132.

35. Kemp J, Despres O, Pebayle T, Dufour A. Differences in age-related effects on myelinated and unmyelinated peripheral fibres: A sensitivity and evoked potentials study. Eur J Pain 2014; 18:482-488. 